This article has been published in a revised form in Journal of Management \& Organization, https://doi.org/10.1017/jmo.2019.56. This version is free to view and download for private research and study only. Not for re-distribution or re-use. (C) Cambridge University Press and Australian and New Zealand Academy of Management 2019. 
Gossiping about outsiders: How time-related work stress among collectivistic employees hinders job performance

Dirk De Clercq

Inam Ul Haq

Muhammad Umer Azeem

Paper accepted for publication in Journal of Management \& Organization 


\title{
Gossiping about outsiders: How time-related work stress among collectivistic employees hinders job performance
}

\begin{abstract}
This study investigates the connection between employees' experience of time-related work stress and their job performance, with a particular focus on the mediating role of their propensity to engage in negative gossip and the moderating role of their collectivistic orientation. Results based on multisource, three-wave data from employees, their peers, and supervisors in Pakistani organizations show that an important reason that time-related work stress might diminish job performance is that employees expend significant energy discussing their negative evaluations of other organizational members with peers, possibly as a way to protect their selfesteem resources. This mediating role of gossip also is invigorated by employees' collectivistic orientation. For organizations, this study identifies a key mechanism —informal conversations with peers about the flaws of others in the organization-by which time-related stress prevents employees from allocating sufficient energy to completing their job tasks, and it reveals that this process is more likely among collectivistic employees.
\end{abstract}

Keywords: time-related work stress; gossip; collectivistic orientation; job performance; conservation of resources theory 


\section{Introduction}

Experiencing resource-draining workplace adversity represents a critical source of concern for employees, because it can hinder the quality of their organizational functioning, their mental well-being, and their performance (Abbas, Raja, Darr, \& Bouckenooghe, 2014; Demsky, Ellis, \& Fritz, 2014; Hobfoll \& Shirom, 2000; Perko, Kinnunen, \& Feldt, 2017; Tang, Au, Schwarzer, \& Schmitz, 2001). Understanding how adverse work circumstances might undermine employees' ability to contribute to the organization accordingly is an important endeavor for organizational decision makers (McCarthy, Trougakos, \& Cheng, 2016; Shaukat, Yousaf, \& Sanders, 2017). For example, when they experience time-related work stress, employees perceive that they have insufficient time to complete their job duties (Durham, Locke, Poon, \& McLeod, 2000; Gärling, Gamble, Fors, \& Hjerm, 2016; Parker \& DeCotiis, 1983). Manifestations of time-related work stress include a conviction that they have too many responsibilities and too little time to fulfill them, a sense that they never have off time during their work hours, or the perception that they work so much that there is insufficient time left for other activities (Bouckenooghe, Raja, Butt, Abbas, \& Bilgrami, 2017; Parker \& DeCotiis, 1983). The experience of time-related work stress threatens employees' well-being by compromising their perceived ability to meet preset performance standards, such that it also generates fears about their future career prospects (Avery, Tonidandel, Volpone, \& Raghuram, 2010; Beck \& Schmidt, 2013; Stiglbauer, 2017).

To complement extant research that details these negative performance consequences of employees' exposure to excessive time pressures, this study proposes an important reason why these experiences diminish job performance — namely, due to employees' tendency to gossip or talk badly about other organizational members (Erdogan, Bauer, \& Walter, 2015), in their effort 
to conserve their feelings of self-worth when faced with a threat of underperformance resulting from their time stress (Hobfoll, 2001). Such negative gossip represents a specific form of deviant behavior, which Robinson and Bennett (1995) categorize according to two dimensions: the seriousness of its harm and the extent to which the behavior harms individuals instead of the organization in general. Negative gossip is a type of deviant behavior whose harmfulness is minor, and it is interpersonal rather than organizational in nature (Robinson \& Bennett, 1995).

We propose that to the extent that employees believe they have insufficient time to complete their job tasks, their resulting fear about their job prospects (Gärling et al., 2016) may fuel their desire to maintain their self-esteem by engaging in negative gossip and pointing out the inadequacies of others (Brady, Brown, \& Liang, 2017; Ellwardt, Wittek, \& Wielers, 2012; Noon \& Delbridge, 1993). Perceptions of workplace adversity create self-depreciating thoughts among employees (Akhtar \& Shaukat, 2016; Firth, Mellor, Moore, \& Loquet, 2004), yet previous research has not investigated how motives to conserve feelings of self-worth might enhance the propensity of time-pressured employees to engage in negative gossip about other organizational members (Erdogan et al., 2015; Kuo, Chang, Quinton, Lu, \& Lee, 2015). This enhanced propensity, somewhat paradoxically, might then decrease employees' own ability to succeed in the execution of their job tasks though, because it requires valuable energy resources (Hobfoll, 2001), in line with the argument that gossipers tend to suffer from enhanced anxiety levels and concerns about their organizational functioning when they talk badly about other organizational members (Jaeger, Skleder, Rind, \& Rosnow, 1994; Michelson \& Mouly, 2004).

In addition, we argue that the mediating role of negative gossip behaviors might be especially salient among employees whose strong collectivistic orientation leads them to protect the interests of their in-group, defined herein as coworkers who belong to their immediate work 
environment, potentially at the expense of outsiders from other work units (Oyserman, Coon, \& Kemmelmeier, 2002; Triandis \& Gelfland, 1998). The tendency toward intergroup competition that marks collectivists - and associated propensities to identify themselves strongly with people in their surrounding work environment but dissociate from outsiders who are more "remote" in the organization (Smith \& Bond, 1993; Triandis, 2001) —might make it more likely that employees engage in negative gossip targeted at outsiders to preserve their self-esteem in the presence of time-related work stress.

\section{COR theory}

To substantiate these theoretical arguments, the current study draws from conservation of resources (COR) theory, which asserts that employees' work behaviors reflect their motivation to prevent resource losses and obtain resource gains (Hobfoll, 1989). A threat of resource loss due to unfavorable work conditions spurs employees to undertake behaviors that counter such an occurrence (Hobfoll \& Shirom, 2000). For example, the threat of not being able to fulfill their job duties due to excessive time pressures may generate a loss of the resource of employees' selfesteem (Ford \& Jin, 2015; Gärling et al., 2016; Höge, 2009). In turn, they may seek to undo that loss by engaging in negative gossip about other members of the organization, to present themselves in a more positive light (Grosser, Lopez-Kidwell, Labianca, \& Ellwardt, 2012; Noon \& Delbridge, 1993). Thus, investing personal energy in negative evaluations of others might help mitigate employees' self-depreciation when they experience significant time stress; however, it also could be detrimental, in that the anxiety and potential for guilt that results from negative work behaviors (Michelson \& Mouly, 2004; Tangney, Wagner, Hill-Barlow, Marschall, \& Gramzow, 1996; Wicker, Payne, \& Morgan, 1983) can leave the actors with insufficient energy 
resources to perform productive activities and meet their performance requirements (Hobfoll \& Shirom, 2000).

Moreover, COR theory suggests that employees' personal characteristics can invigorate the processes that seek to generate resources in response to the threat of resource-depleting work conditions (Hobfoll, 2001; Hobfoll \& Shirom, 2000). In particular, employees' collectivistic orientation might generate personal satisfaction with gossip as a response to time-related work stress, because their desire to distinguish themselves from and compete with outsiders, and associated motivation to protect the interests of their in-group, means that time-pressured employees likely recognize the benefits of maintaining their collective standing by highlighting the inadequacies of outsiders (Gundlach, Zivnuska, \& Stoner, 2006; Noon \& Delbridge, 1993). In short, this study investigates how the personal characteristic of a collectivistic orientation might stimulate the translation of employees' time-related work stress into negative gossip about others and thus their poorer job performance.

\section{Contributions}

This study seeks to make several contributions. First, by drawing from COR theory, it clarifies how the experience of time-related work stress can diminish employees' job performance, because they devote energy-consuming efforts to negative evaluations of other organizational members (Erdogan et al., 2015), in an attempt to underscore their flaws while conserving their own self-esteem (Hobfoll \& Shirom, 2000; Wert \& Salovey, 2004). This behavioral response to excessive time pressures can undermine employees' ability to perform their job tasks, because they spend so much valuable energy gossiping with peers about the negative features of other members (Quinn, Spreitzer, \& Lam, 2012). That is, significant efforts to underscore the shortcomings of other organizational members may distract them from 
performing their own job duties (Brady et al., 2017; Grosser et al., 2012; Hockey, 1997). The propensity to elaborate on others' flaws in conversations with peers is an unexplored mechanism through which time-related work stress might cause employees to underperform. Notably, by pinpointing the critical role of negative gossip behavior in connecting time-related work stress with reduced job performance, we complement evidence regarding the potentially positive outcomes of gossip, such that it might spur intra-organizational information exchanges or provide opportunities to vent work-related frustrations (Beersma \& Van Kleef, 2011; Feinberg, Willer, Stellar, \& Keltner, 2012). This study instead acknowledges the dark side of gossip and its potentially negative performance consequences, as informed by the enhanced stress levels that it generates (Bergmann, 1993; Jaeger et al., 1994; Michelson \& Mouly, 2004) and the possibility that this behavior might be perceived as dysfunctional or subversive by other organizational members (Erdogan et al., 2015; Farley, 2011; Grosser, Lopez-Kidwell, \& Labianca, 2010).

Second, this study advances prior research by examining when the translation of timerelated work stress into diminished job performance through negative gossip might be more likely. Previous research suggests that employees' collectivistic orientation increases their propensity to protect the interests of their immediate peers, such that they compare the accomplishments of their in-group with those of out-group members (Lam, Liu, \& Loi, 2016; Oyserman et al., 2002) and accentuate the competition for organizational rewards (Gomez, Kirkman, \& Shapiro, 2000; Smith \& Bond, 1993). By addressing a more indirect influence of this personal characteristic, we predict that it catalyzes a sense of personal satisfaction when time-pressured employees seek to enhance their relative attractiveness with negative gossip about others (Grosser et al., 2012; Noon \& Delbridge, 1993). In turn, to the extent that employees' collectivistic orientation invigorates the positive effect of resource-draining time 
stress on their negative gossip behaviors, it may further undermine their ability to devote sufficient energy to performance-enhancing activities (Hobfoll \& Shirom, 2000; Quinn et al. 2012). The consideration of this potential role of a collectivistic orientation also extends previous studies of the contingent roles of other personal characteristics, such as a power distance orientation (Lin, Wang, \& Chen, 2013) or conscientiousness (Taylor \& Kluemper, 2012), in terms of how employees react to resource-draining work conditions.

Third, this research responds to calls for studies of job stress in organizations in nonWestern settings (De Clercq, Haq, \& Azeem, 2017; Jam, Donia, Raja, \& Ling, 2017; Jamal, 2010; So, West, \& Dawson, 2011). The empirical context is Pakistan, a country marked by high levels of uncertainty avoidance (Hofstede, Hofstede, \& Minkov, 2010). People in cultures that tend to avoid risk often feel threatened when they must operate in resource-draining work conditions (Abbas et al., 2014), so their motivation to conserve their self-esteem resources by emphasizing the inadequacies of other organizational members might be stronger. Moreover, the study of collectivistic orientation, as a critical personal feature, should be highly relevant in Pakistani culture, with its high scores on collectivism (Hofstede et al., 2010), though previous research also cites the wide variation within any a particular country in how individual members score on their countries' average cultural values (Hui \& Triandis 1986; Oyserman et al., 2002). Therefore, our focus on the role of employees' collectivistic orientation for invigorating the influence of time-related work stress on their gossip behaviors and reduced job performance is highly relevant in this context and for other countries with similar cultural profiles.

As the conceptual framework in Figure 1 predicts, employees' experience of time-related work stress should stimulate their engagement in gossip behaviors with peers, which diminish their ability to dedicate significant energy to meeting their job requirements. Thus, the time 
invested in negative evaluations of others helps explain why time-related work stress diminishes job performance. Employees' collectivistic orientation in turn serves as a trigger, such that the conversion of time-related work stress into reduced job performance, through negative gossip behavior, becomes more likely when employees emphasize in-group over out-group interests. [Insert Figure 1 about here]

\section{Hypotheses}

Mediating role of negative gossip with peers

According to COR theory, employees seek to protect their personal resource bases in the presence of work adversity (Hobfoll, 1989, 2001). Notably, the frustration they suffer when they have insufficient time to complete their job tasks threatens their self-worth, because they perceive themselves as incapable of meeting the expectations that their organization has set forth (Beck \& Schmidt, 2013; Gärling et al., 2016; Höge, 2009). Therefore, time-pressured employees may desire to emphasize how other organizational members might be performing even worse than they are (Erdogan et al., 2015), because such negative evaluations help them conserve or protect their personal self-esteem resources (Avery et al., 2010; Hobfoll, 2001; Russ-Eft, 2001). This process transfers the focus, from their own inadequacies to those of other people in the organization, thereby preserving feelings of self-worth (Brady et al., 2017; Noon \& Delbridge, 1993). Ultimately, employees may maintain a more positive image of themselves, even if they

cannot handle the time pressures they face, if they shift attention to the failures of others instead of their own (Grosser et al., 2012; Kuo et al., 2015).

Hypothesis 1: There is a positive relationship between employees' experience of timerelated work stress and their undertaking of negative gossip with peers.

Yet this negative behavior also could harm their job performance. According to COR theory, employees' allocation of personal energy resources to negative work behaviors, such as 
spreading negative rumors about others' shortcomings (Erdogan et al., 2015), leaves them with less energy to undertake productive, performance-enhancing activities (Grosser et al., 2012; Hobfoll, 2001). This energy-draining effect might stem from gossipers' worries about the quality of their organizational functioning (Jaeger et al., 1994; Michelson \& Mouly, 2004) or sense of guilt and shame (Tangney et al., 1996; Wicker et al., 1983), which in turn might relate to their reduced likeability (Farley, 2001) and less central positions in the intra-organizational network (Erdogan et al., 2015). Thus, their efforts to emphasize the failures of other organizational members might diminish employees' own job performance, because of the energy depletion that comes with concerns about how they are perceived by other members, including the targets of their gossip but also supervisors (Bergmann, 1993; Erdogan et al., 2015; Farley, 2001); such energy cannot be allocated to their job tasks. Conversely, employees who refrain from negative gossip likely can devote more resources to productive activities that help them meet their performance requirements (Hobfoll \& Shirom, 2000; Noon \& Delbridge, 1993). That is, when employees are not distracted by sharing their negative evaluations of others with peers, they can devote sufficient energy to activities that help them complete their job tasks (Quinn et al., 2012). Consistent with these arguments,

Hypothesis 2: There is a negative relationship between employees' negative gossip behavior with peers and their job performance.

The combination of these arguments suggests a critical mediating role of negative gossip behavior, such that it provides an explanatory mechanism for why the experience of time-related work stress undermines employees' job performance. If employees who feel pressured by excessive time constraints devote significant energy to emphasizing the shortcomings of other organizational members, as a mechanism to conserve their feelings of self-worth (Avery et al., 2010; Ellwardt et al., 2012), it leaves them with less energy to undertake productive activities 
(Hobfoll \& Shirom, 2000). Thus, suffering from time-related work stress may diminish job performance, because this adverse work condition steers employees to gossip about other members, rather than performing their job responsibilities (Quinn et al., 2012). Previous research proposes mediating roles of other factors in this link between time stress and negative work outcomes, such as state-level goal orientations (Beck \& Schmidt, 2013) and job satisfaction (Silla \& Gamero, 2014). As an extension, this study predicts that engaging in gossip mediates the effect of time-related work stress on job performance.

Hypothesis 3: Employees' negative gossip behavior with peers mediates the relationship between their experience of time-related work stress and their job performance.

\section{Moderating role of collectivistic orientation}

According to COR theory, the motivation to conserve feelings of self-worth by undertaking negative gossip behaviors in response to time-related work stress should be reinforced by personal factors that generate positive feelings in response to such activities (Hobfoll, 2001; Hobfoll \& Shirom, 2000). We argue, then, that employees with a strong collectivistic orientation might enjoy spreading negative rumors about others in the organization when they suffer from time-related work stress, because doing so appears to be an acceptable, desirable response (Oyserman et al., 2002; Triandis, 2001). A notable characteristic of people with a strong collectivistic orientation is that they behave distinctively in relation to their ingroup compared with out-groups (Smith \& Bond, 1993). The behavioral outcomes of this personal characteristic thus are contingent on the specific target, underscoring the importance of the identities of others with whom a person might be collectivistic (Hui \& Triandis, 1986). In particular, collectivistic employees tend to value close collaboration with people in their immediate work environment but compete with or distinguish themselves from outsiders beyond their inner circle (Gomez et al., 2000; Triandis, Bontempo, Villareal, Asai, \& Lucca, 1988). 
In the context of this study, we postulate that employees who suffer from severe time pressures and have a strong collectivistic orientation may experience a strong sense of personal fulfillment when they shift attention away from their own inadequacies to the failures of other members who do not belong to their immediate work environment (Oyserman, 1993; Ryan \& Deci, 2000). In particular, employees with a strong collectivistic orientation tend to be energized by contrasting their own and their in-group's performance against the performance of out-groups in the same organization, who are seen as competitors (Gundlach et al., 2006; Oyserman et al., 2002), so they may feel particularly excited about underscoring these failures during peer conversations, as a mechanism to conserve their self-esteem (Gärling et al., 2016; Stiglbauer, 2017). Conversely, employees with a weak collectivistic orientation should derive less personal satisfaction from responding to this threat by highlighting the shortcomings of others, so they may be less likely to react to a resource-draining work situation by gossiping (Hobfoll \& Shirom, 2000). They have less need to distinguish their own or in-group competencies from those of outsiders (Triandis \& Gelfland, 1998; van Dyne, Vandewalle, Kostova, Latham, \& Cummings, 2000) and thus should be less likely to invest personal energy to underscore the shortcomings of outsiders in conversations with peers. Formally,

Hypothesis 4: The positive relationship between employees' experience of time-related work stress and negative gossip behavior with peers is moderated by their collectivistic orientation, such that this relationship is invigorated for employees with a stronger collectivistic orientation.

These arguments also indicate the presence of moderated mediation (Preacher, Rucker, \& Hayes, 2007), such that employees' collectivistic orientation is a contingent factor that determines the indirect effect of their experience of time-related work stress on their job performance, through gossip behavior. For employees who derive personal satisfaction from comparing themselves and immediate peers with others who do not belong to their inner circle, 
discussing negative evaluations of those outsiders with peers should be a particularly important mechanism to conserve their self-esteem resources (Hobfoll, 2001; Hobfoll \& Shirom, 2000) and explain why they cannot meet their performance requirements (Beck \& Schmidt, 2013; Silla \& Gamero, 2014). Conversely, if employees lack a strong tendency to contrast in-group performance with that of outsiders, the need to engage in gossip with peers to protect their selfesteem resources becomes less important, in terms of explaining how the experience of timerelated work stress contributes to their diminished job performance (Hobfoll, 2001).

Hypothesis 5: The indirect relationship between employees' experience of time-related work stress and their job performance, through enhanced negative gossip behavior with peers, is moderated by their collectivistic orientation, such that this indirect relationship is invigorated for employees with a stronger collectivistic orientation.

\section{Research method}

\section{Sample and data collection}

We collected data from employees in 10 organizations in Pakistan, operating in four industry sectors, namely, automotive, banking, education, and textiles. The research design entailed three waves, with a time lag of two weeks between each wave. Although reverse causality cannot be completely ruled out with this relatively short time lag, the gaps reduce this risk, compared with cross-sectional designs. The surveys were written in English, which is the official language of business and education in Pakistan. During each round, the participants were guaranteed complete confidentiality; no individual identifying information would ever be communicated, and they could withdraw from the research whenever they wished. The surveys also emphasized that there were no right or wrong answers, that participants would vary in their answers to the questions, and that it was instrumental that their answers reflected their true opinions - measures that help diminish the likelihood of social desirability and acquiescence biases (Spector, 2006). 
The first survey wave asked employees to assess their time-related work stress and collectivistic orientation. The second wave captured their negative gossip behaviors, as assessed by randomly selected peers. These peers worked in the same department as the employees who participated in the first wave, and they had to have worked with these employees for at least six months, so they had sufficient knowledge about their colleagues' work behaviors. Each peer rated no more than two employees, to prevent data nesting, consistent with previous research (Naseer, Raja, \& Donia, 2016). In the third survey, the supervisors of the employees rated their job performance. Of the 400 originally administered surveys, we received 198 completed sets, for a response rate of $50 \%$. The employee sample had the following characteristics: $10 \%$ were women, their average age was 32 years, and they had worked in their current job for an average of eight years.

Measures

The measures of the focal constructs include items validated by previous research, as detailed next. The scales used five-point Likert anchors that ranged from 1 ("strongly disagree") to 5 ("strongly agree").

Time-related work stress. We assessed employees' experience of time-related work stress with an eight-item scale developed by Parker and DeCotiis (1983) and used in previous research (e.g., Bouckenooghe et al., 2017). For example, employees responded to the following statements: "I have too much work and too little time to do it in," "I spend so much time at work that I can't see the forest for the trees," and "I feel like I never have a day off” (Cronbach's alpha $=.84)$.

Collectivistic orientation. We measured employees' collectivistic orientation with a fouritem scale of horizontal collectivism, developed by Triandis and Gelfland (1998). This measure 
captures the extent to which employees see themselves and their peers as part of a collective of equal others. The survey emphasized that the items pertained to how employees feel about colleagues in their immediate work environment, such that they assessed their agreement with statements such as, "The well-being of my peers is important to me," "If a peer gets a prize, I would feel proud," and "I feel good when I cooperate with peers" (Cronbach's alpha $=.70)$.

Negative gossip behavior. To measure employees' engagement in negative evaluations of other organizational members, we applied a four-item gossip scale developed by Erdogan et al. (2015), assessed by peers who had worked with the focal employees for at least six months in the same department. The items were preceded by a statement that explained that the term "peers" refers to any colleagues who belong to the employees' immediate work environment, whereas “other organizational members" are people outside this work environment. Example items were, "This employee talks with his/her peers about the mistakes of other organizational members," "This employee talks with his/her peers about the poor performance of other organizational members," and "This employee talks with his/her peers about the failures of other organizational members" (Cronbach's alpha $=.91)$.

Job performance. To assess supervisor-rated job performance, we applied a previously validated seven-item scale developed by Williams and Anderson (1991). Sample items included, "This employee adequately completes his/her assigned duties," "This employee meets the formal performance requirements of his/her job," and "This employee fulfills the responsibilities specified in his/her job descriptions" (Cronbach's alpha $=.79$ ).

Control variables. The analyses also included four control variables: gender ( $1=$ female $)$, age (in years), organizational tenure (in years), and industry (using three dummies for automotive, banking, and education, with textiles as the base category). 


\section{Results}

Table 1 provides the correlation coefficients and descriptive statistics, and Table 2 features the hierarchical regression results. Models 1-3 predict negative gossip behavior, and Models 4-6 predict job performance. For each model, the variance inflation factor values were lower than 5.0, so multicollinearity is not a concern (Aiken \& West, 1991).

[Insert Tables 1 and 2 about here]

Hypothesis 1 predicted that employees who suffer from excessive time pressures would be more likely to spend significant energy talking negatively about other organizational members during their conversations with peers. The positive relationship between time-related work stress and negative gossip behavior in Model 2 confirms this prediction $(\beta=.306, p<.01)$. In support of Hypothesis 2, negative gossip prevents employees from allocating sufficient energy to performance-enhancing activities, as evidenced in the negative relationship between gossip behavior and job performance in Model $5(\beta=-.293, p<.001)$.

The assessment of the mediating role of negative gossip behavior relied on the bootstrapping method developed by Preacher and Hayes (2004) and the Process macro developed by Hayes (2013). This method provides confidence intervals (CIs) for the indirect effect of time-related work stress on job performance, thereby avoiding the statistical power problems that might arise due to asymmetric or other non-normal sampling distributions of the indirect effect (MacKinnon, Lockwood, \& Williams, 2004). With 10,000 random samples and replacement from the full sample (Shrout \& Bolger, 2002), the CI for the indirect effect of timerelated work stress on job performance through negative gossip behavior did not include 0 [$.100 ;-.018]$, which affirms the presence of mediation. 
The test of the moderating effect of collectivistic orientation advanced in Hypothesis 4 relies on the interaction term of time-related work stress $\times$ collectivistic orientation to predict negative gossip behavior (Model 3). This interaction term is significant $(\beta=.266, p<.05)$, as depicted in the relationship between time-related work stress and negative gossip behavior in Figure 2 at high and low levels of collectivistic orientation, according to a simple slope analysis (Aiken \& West, 1991). According to this analysis, the relationship between time-related work stress and negative gossip behavior is positive and significant at high levels of collectivistic orientation $(\beta=.492, p<.001)$ but not at low levels $(\beta=-.040, n s)$, in line with Hypothesis 4 .

\section{[Insert Figure 2 about here]}

Finally, the test for the presence of moderation mediation also drew on Preacher et al.'s (2007) method and Hayes's (2013) Process macro. Similar to the bootstrapping approach used to assess mediation, this method generates CIs rather than point estimates for the conditional indirect effects (MacKinnon et al., 2004). As specified in Hayes's (2013) process macro, the CIs pertain to different levels of the moderator (i.e., 10th, 25 th, 75 th, and 90 th percentiles). ${ }^{1}$ The bootstrap 95\% CIs for the conditional indirect effect of time-related work stress on job performance at the 10th and 25th percentiles contained $0([-.059, .046]$ and $[-.069, .010]$, respectively), but the intervals did not contain 0 at the 75 th and 90 th percentiles of collectivistic orientation ([-.109, -.019] and [-.150, -.028], respectively). Furthermore, the CI of the index of moderated mediation (Hayes, 2015) did not include 0 ([-.094; -.002]). Thus, collectivistic orientation invigorated the negative indirect effect of time-related work stress on job performance, through gossip, in support of Hypothesis 5 and the overall conceptual framework.

\footnotetext{
${ }^{1}$ In line with the theoretical framework, the model included a moderating effect of collectivistic orientation on the relationship between time-related work stress and negative gossip behavior but not between negative gossip behavior and job performance. A post hoc test affirmed that collectivistic orientation did not significantly influence this second relationship.
} 


\section{Discussion}

This study extends previous research by examining the link between time-related work stress and job performance, with a particular focus on unexplored factors that might explain or influence this process. Consistent with COR theory (Hobfoll, 1989, 2001; Hobfoll \& Shirom, 2000), evaluations shared with peers about the shortcomings of other organizational members (Erdogan et al., 2015) represent critical mechanisms that explain why the threat of excessive time pressures leads to reduced job performance, in that they help conserve employees' self-esteem resources in the presence of resource-draining time stress (Höge, 2009; Wert \& Salovey, 2004) but simultaneously deplete their energy reservoirs for productive, performance-enhancing activities (Quinn et al., 2012). This mediating role also is particularly prominent among employees with a strong collectivistic orientation (Triandis, 2001).

Previous studies consider various negative outcomes of the experience of time-related work stress, such as burnout (McGregor, Magee, Caputi, \& Iverson, 2016), reduced mental wellbeing (Stiglbauer, 2017), depressive symptoms (Ford \& Jin, 2015), and diminished performance (Beck \& Schmidt, 2013), but not how such work stress may hamper job performance because of employees' propensity to allocate significant energy to negative work behaviors. To fill this gap, this study reveals that employees' exposure to excessive time pressures may compromise their job performance because they respond by attempting to protect their self-esteem resources by elaborating on others' shortcomings (Erdogan et al., 2015). Informal conversations about other people's inadequacies or underperformance, even if meant to make the time-pressured employees feel good about themselves (Grosser et al., 2012; Noon \& Delbridge, 1993), actually deplete their energy and prevent them from devoting sufficient resources to meeting their performance requirements (Hobfoll \& Shirom, 2000), consistent with previous studies that point 
to gossipers' enhanced anxiety levels when they are perceived as less likeable or powerful by other members (Erdogan et al., 2015; Farley, 2011; Michelson \& Mouly, 2004). That is, gossip might help time-pressured employees cope with self-depreciating thoughts and forget about their own failures (Beck \& Schmidt, 2013; Elfering, Grebner, \& de Tribolet-Hardy, 2013), but the associated energy depletion also makes it less likely that they can devote sufficient effort to positive, performance-enhancing activities.

This mediating role of gossip behavior in turn is moderated by employees' collectivistic orientation, a personal characteristic that generates resource gains (i.e., personal satisfaction) when time-pressured employees compare themselves with other organizational members who do not belong to their in-group (Oyserman et al., 2002; Triandis, 2001). Negative gossip with immediate peers links the experience of time-related work stress to reduced job performance more powerfully if employees bring up the inadequacies of other organizational members during these conversations (Erdogan et al., 2015). In elucidating this moderated mediation effect, the current study shows how the likelihood that time-pressured employees' negative evaluations of others - as a means to conserve their feelings of self-worth by shifting attention away from their own inadequacies to those of other members - can escalate into even lower job performance if their collectivistic orientation fuels their desire to spread negative rumors (Oyserman, 2002).

In summary, this study offers an elaborated understanding of the factors that influence the connection between time-related work stress and job performance. It contributes to extant research by showing how (1) the significant allocation of energy to engaging in gossip functions as a critical mechanism that links an important source of workplace adversity (time stress) to reduced job performance and (2) employees' collectivistic orientation triggers this process.

\section{Limitations and future research}


This study has some limitations that suggest avenues for further research. First, the focus on gossip as a prominent causal mechanism for explaining the harmful role of time-related work stress on job performance was informed by the need to investigate how negative work behaviors, in response to workplace adversity, prevent employees from allocating their energy to productive, performance-enhancing activities (Berry, Carpenter, \& Barratt, 2012; Cohen, 2016). However, other mediating mechanisms might have influences as well, including negative work attitudes such as job dissatisfaction (Turnley \& Feldman, 2000) or work disengagement (Aslam, Muqadas, Imran, \& Rahman, 2018). An interesting extension would be to investigate the mediating effect of more "extreme" manifestations of organizational deviance, such as property damage or personal aggression (Robinson \& Bennett, 1995). For example, reduced job performance, in reaction to excessive time pressures, might be greater to the extent that employees respond to time pressures with deviant behaviors that are more aggressive and energy-consuming (Quinn et al., 2012). In this sense, our focus on negative gossip as a "mild" form of deviant behavior (Robinson \& Bennett, 1995) represents a conservative test of the theoretical arguments.

In a related vein, this study does not provide a direct measure of the theorized focal mechanism that links time-related work stress and gossip behavior, namely, the desire to conserve feelings of self-worth. Nor does it measure the energy depletion that underpins the negative relationship between gossip behavior and job performance. These mechanisms are grounded in the well-established COR theory - that is, employees exposed to resource-draining work conditions seek to mitigate resource losses with specific behaviors, yet these behaviors in turn can deplete the energy resources that employees need to perform their job duties (Hobfoll, 2001; Hobfoll \& Shirom, 2000) - but further investigations could assess them more directly. For 
example, it would be interesting to study why, or in what circumstances, the energy-draining, performance-reducing effect of talking badly about colleagues, as empirically found herein, might be countered by a sense of relief when employees can vent their frustrations about adverse work conditions in the form of gossiping behavior (Beersma \& Van Kleef, 2011).

Second, collectivistic orientation is a critical contingency factor that invigorates the indirect relationship between the experience of time-related work stress and reduced job performance, but further investigations could consider the influences of other personal factors. For example, employees' neuroticism (De Hoogh \& Den Hartog, 2009) or Machiavellianism (Zagenczyk, Restubog, Kiewitz, Kiazad, \& Tang, 2014), might catalyze the translation of timerelated work stress into negative gossip behavior and lower job performance. Negative organizational factors also could lead employees to let their frustration with time pressures escalate into gossip behavior, such as an organizational climate marked by dysfunctional politics (Abbas et al., 2014) or strong internal rivalry for company resources (Luo, Slotegraaf, \& Pan, 2006).

Third, our sample consists of organizations that operate in four different industries, and we accordingly controlled for industry. Finding empirical support for the theorized relationships, after accounting for industry effects, implies that the effects of the focal variables are robust, irrespective of pertinent industry-specific factors. Nonetheless, we acknowledge the possibility of omitted variable bias, so continued studies might test additional variables that speak to the professional cultures or the preferred organizational designs that permeate a particular industry, such as the extent to which established industry practices support excessive time pressures or embrace group harmony and intra-organizational collaboration versus competition. Furthermore, an organization's internal work culture might be directly influenced by the competitive dynamics 
in its industry, so it would be useful to investigate relevant factors, such as the extent of market dynamism or competitive rivalry in the industry (Cui, Griffith, \& Cavusgil, 2005). Perhaps employees whose organizations operate in industries with unpredictable or intensive competitive dynamics appreciate that their employer needs to impose stringent time pressures on its employee bases, to survive in the external market (Lahiri, Pérez-Nordtvedt, \& Renn, 2008). The likelihood that they respond to individual frustrations about excessive time pressures with negative gossip behavior might be subdued in this scenario.

Fourth, this study took place in one country. The characteristics of Pakistani culture (i.e., high uncertainty avoidance and collectivism) make it highly pertinent for examining the proposed theoretical framework (Hofstede et al., 2010). The conceptual arguments are not tied to any specific country though, so the strength but not the nature of the hypothesized relationships may vary across country settings. Nonetheless, it would be interesting to undertake cross-country comparisons to assess whether and how the experience of time-related work stress may spur employees to engage in negative evaluations of other organizational members, as well as the role that different moderators might play in this process, in cultural contexts other than Pakistan. Such comparisons could test the robustness of the hypothesized relationships across countries, as well as investigate the possible interplay between individual- and country-level cultural factors in terms of how employees react to stressful work conditions.

\section{Practical implications}

Organizations should be cognizant that a substantial source of workplace adversity arises from employees' stress about having insufficient time to meet their job obligations, and these feelings can spill over into negative work behaviors such as emphasizing other organizational members' inadequacies and failures. Managers accordingly should seek to diminish time stress, 
though such efforts likely are complicated, because employees often are reluctant to admit that they cannot complete their job duties in the time allotted, to avoid perceptions of incompetency or unfavorable performance evaluations (Avery et al., 2010). Through proactive efforts to identify excessive workloads and employees who suffer from severe time pressures, organizations might establish more specific, transparent job guidelines, especially among new hires (Saks, Uggerslev, \& Fassina, 2007). Training programs for newcomers could clearly explain expected performance targets and the paths by which employees can achieve these targets, to increase their ability to manage their time effectively.

Yet the presence of some time-related work stress might not be avoidable, particularly when external competitive pressures or work complexity is substantial (Avery et al., 2010; Gärling et al., 2016). This study shows that when employees feel stressed about having insufficient time to complete their job tasks, the conversion of that stress into dysfunctional gossip might be limited if the company seeks out employees who lack the natural tendency to speak badly about out-group members as a mechanism to protect their own and in-group interests. Moreover, organizational decision makers should seek to match employees' immediate work context with appropriate selection mechanisms for particular work projects. For example, assigning employees who derive little joy from spending significant time gossiping about others behind their backs to projects with strict deadlines could reduce the likelihood that the time pressures will lead to derogatory comments about others' inadequacies. Conversely, to the extent that employees derive personal joy from contrasting their in-group performance with that of outsiders, organizations might suffer more from harmful gossip if these employees experience significant time-related work stress, so they should actively seek to reduce such pressures.

\section{Conclusion}


This study extends previous research by investigating the harmful effect of employees' time-related work stress on job performance, as well as the role that their gossip behavior and collectivistic orientations play in this process. The tendency to engage in negative evaluations of others' shortcomings represents an important path by which the threat of excessive time pressures thwarts the ability to complete job tasks. The strength of this explanatory mechanism also increases to the extent that employees are collectivistic and feel energized by speaking negatively about outsiders. In turn, this study might serve as a platform for further research on how organizations can avoid the detrimental consequences of negative gossip, as well as its causes, such that employees can dedicate sufficient energy to positive, performance-enhancing activities, even in the presence of unfavorable work conditions. 


\section{References}

Abbas, M., Raja, U., Darr, W., \& Bouckenooghe, D. (2014). Combined effects of perceived politics and psychological capital on job satisfaction, turnover intentions, and performance. Journal of Management, 40, 1813-1830.

Aiken, L.S., \& West, S.G. (1991). Multiple regression: Testing and interpreting interactions. Newbury Park, CA: Sage.

Akhtar, S., \& Shaukat, K. (2016). Impact of petty tyranny on alienation from work: Role of selfesteem and power-distance. Global Journal of Flexible Systems Management, 17, 275-285.

Aslam, U., Muqadas, F., Imran, M.K., \& Rahman, U.U. (2018). Investigating the antecedents of work disengagement in the workplace. Journal of Management Development, 37, 149-164.

Avery, D.R., Tonidandel, S., Volpone, S.D., \& Raghuram, A. (2010). Overworked in America? How work hours, immigrant status, and interpersonal justice affect perceived work overload. Journal of Managerial Psychology, 25, 133-147.

Beck, J.W., \& Schmidt, A.M. (2013). State-level goal orientations as mediators of the relationship between time pressure and performance: A longitudinal study. Journal of Applied Psychology, 98, 354-363.

Beersma, B., \& Van Kleef, G.A. (2011). How the grapevine keeps you in line: Gossip increases contributions to the group. Social Psychological and Personality Science, 2, 642-649.

Bergmann, J. R. (1993). Discreet indiscretions: The social organization of gossip. New York: Aldinede Gruyter.

Berry, C.M., Carpenter, N.C., \& Barratt, C.L. (2012). Do other-reports of counterproductive work behavior provide an incremental contribution over self-reports? A meta-analytic comparison. Journal of Applied Psychology, 97, 613-636. 
Bouckenooghe, D., Raja, U., Butt, A.N., Abbas, M., \& Bilgrami, S. (2017). Unpacking the curvilinear relationship between negative affectivity, performance, and turnover intentions: The moderating effect of time-related work stress. Journal of Management and Organization, 23, 373-391.

Brady, D.L., Brown, D.J., \& Liang, L.H. (2017). Moving beyond assumptions of deviance: The reconceptualization and measurement of workplace gossip. Journal of Applied Psychology, $102,1-25$.

Cohen, A. (2016). Are they among us? A conceptual framework of the relationship between the dark triad personality and counterproductive work behaviors (CWBs). Human Resource Management Review, 26, 69-85.

Cui, A.S., Griffith, D.A., \& Cavusgil, S.T. (2005). The influence of competitive intensity and market dynamism on knowledge management capabilities of multinational corporation subsidiaries. Journal of International Marketing, 13, 32-53.

De Clercq, D., Haq, I.U., \& Azeem, M.U. (2017). Perceived threats of terrorism and job performance: The roles of job-related anxiety and religiousness. Journal of Business Research, 78, 23-32.

De Hoogh, A.H.B., \& Den Hartog, Deanne N. (2009). Neuroticism and locus of control as moderators of the relationships of charismatic and autocratic leadership with burnout. Journal of Applied Psychology, 94, 1058-1067.

Demsky, C.A., Ellis, A.M., \& Fritz, C. (2014). Shrugging it off: does psychological detachment from work mediate the relationship between workplace aggression and work-family conflict? Journal of Occupational Health Psychology, 19, 195-205. 
Durham, C.C., Locke, E.A., Poon, J.L., \& McLeod, P.L. (2000). Effects of group goals and time pressure on group efficacy, information-seeking strategy, and performance. Human Performance, 13, 115-138.

Elfering, A., Grebner, S., \& de Tribolet-Hardy, F. (2013). The long arm of time pressure at work: Cognitive failure and commuting near-accidents. European Journal of Work and Organizational Psychology, 22, 737-749.

Ellwardt, L., Wittek, R., \& Wielers, R. (2012). Talking about the boss: Effects of generalized and interpersonal trust on workplace gossip. Group \& Organization Management, 37, 521-549.

Erdogan, B., Bauer, T.N., \& Walter, J. (2015). Deeds that help and words that hurt: Helping and gossip as moderators of the relationship between leader-member exchange and advice network centrality. Personnel Psychology, 68, 185-214.

Farley, S.D. (2011). Is gossip power? The inverse relationships between gossip, power, and likability. European Journal of Social Psychology, 41, 574-579.

Feinberg, M., Willer, R., Stellar, J., \& Keltner, D. (2012). The virtues of gossip: Reputational information sharing as prosocial behavior. Journal of Personality and Social Psychology, 102, 1015-1030.

Firth, L., Mellor, D.J., Moore, K.A., \& Loquet, C. (2004). How can managers reduce employee intention to quit? Journal of Managerial Psychology, 19, 170-187.

Ford, M.T., \& Jin, J. (2015). Incongruence between workload and occupational norms for time pressure predicts depressive symptoms. European Journal of Work and Organizational Psychology, 24, 88-100. 
Gärling, T., Gamble, A., Fors, F., \& Hjerm, M. (2016). Emotional well-being related to time pressure, impediment to goal progress, and stress-related symptoms. Journal of Happiness Studies, 17, 1789-1799.

Gomez, C., Kirkman, B.L. \& Shaprio, D.L. (2000) Reward allocation preferences in Mexico and the United States: The effects of ingroup/outgroup status and collectivism. Academy of Management Journal, 43, 1097-1106.

Grosser, T.J., Lopez-Kidwell, V., \& Labianca, G. (2010). A social network analysis of positive and negative gossip in organizational life. Group \& Organization Management, 35, 177-212.

Grosser, T.J., Lopez-Kidwell, V., Labianca, G., \& Ellwardt, L. (2012). Hearing it through the grapevine: Positive and negative workplace gossip. Organizational Dynamics, 41, 52-61.

Gundlach, M., Zivnuska, S., \& Stoner, J. (2006). Understanding the relationship between individualism-collectivism and team performance through an integration of social identity theory and the social relations model. Human Relations, 59, 1603-1632.

Hayes, A.F. (2013). Introduction to mediation, moderation, and conditional process analysis: A regression-based approach. New York: Guilford Press.

Hayes, A.F. (2015). An index and test of linear moderated mediation. Multivariate Behavioral Research, 50, 1-22.

Hobfoll, S.E. (1989). Conservation of resources. A new attempt at conceptualizing stress. American Psychologist, 44, 513-524.

Hobfoll, S.E. (2001). The influence of culture, community, and the nested-self in the stress process: Advancing conservation of resource theory. Applied Psychology: An International Review, 50, 337-369. 
Hobfoll, S.E., \& Shirom, A. (2000). Conservation of resources theory: Applications to stress and management in the workplace. In R. T. Golembiewski (Ed.), Handbook of organization behavior (pp. 57-8 1). New York: Dekker.

Hockey, G.R. (1997). Compensatory control in the regulation of human performance under stress and high workload: A cognitive-energetical framework. Biological Psychology, 45, 73-93.

Hofstede, G.H., Hofstede, G.J., \& Minkov, M. (2010). Cultures and organizations: Software of the mind. Intercultural cooperation and its importance for survival ( $3^{\text {rd }}$ ed.). New York: McGraw-Hill.

Höge, T. (2009). When work strain transcends psychological boundaries: An inquiry into the relationship between time pressure, irritation, work-family conflict and psychosomatic complaints. Stress and Health: Journal of the International Society for the Investigation of Stress, 25, 41-51.

Hui, C.H., \& Triandis, H.C. (1986). Individualism-collectivism: A study of cross-cultural researchers. Journal of Cross Cultural Psychology, 17, 225-248.

Jaeger, M.E., Skleder, A.A., Rind, B., \& Rosnow, R L. (1994). Gossip, gossipers, gossipees. In R.F. Goodman \& A. Ben-Ze'ev (Eds.), Good gossip (pp. 11-24), Lawrence, KS: University Press of Kansas.

Jam, F.A., Donia, M.B.L., Raja, U., \& Ling, C.H. (2017). A time-lagged study on the moderating role of overall satisfaction in perceived politics: Job outcomes relationships. Journal of Management and Organization, 23, 321-336.

Jamal, M. (2010). Burnout among Canadian, Chinese, Malaysian and Pakistani employees: An empirical examination. International Management Review, 6, 31-41. 
Kuo, C.-C., Chang, K., Quinton, S., Lu, C.-Y., \& Lee, I. (2015). Gossip in the workplace and the implications for HR management: a study of gossip and its relationship to employee cynicism. International Journal of Human Resource Management, 26, 2288-2307.

Lahiri, S., Pérez-Nordtvedt, L., \& Renn, R.W. (2008). Will the new competitive landscape cause your firm's decline? It depends on your mindset. Business Horizons, 51, 311-320.

Lam, L.W., Liu, Y., \& Loi, R. (2016). Looking intra-organizationally for identity cues: Whether perceived organizational support shapes employees' organizational identification. Human Relations, 69, 345-367.

Lin, W., Wang, L., \& Chen, S. (2013). Abusive supervision and employee well-Being: The moderating effect of power distance Orientation. Applied Psychology: An International Review, 62, 308-329.

Luo, X., Slotegraaf, R.J., \& Pan, X. (2006). Cross-functional "coopetition": The simultaneous role of cooperation and competition within firms. Journal of Marketing 70, 67-80.

MacKinnon, D.P., Lockwood, C.M., \& Williams, J. (2004). Confidence limits for the indirect effect. Multivariate Behavioral Research, 39, 99-128.

McCarthy, J.M., Trougakos, J.P., \& Cheng, B.H. (2016). Are anxious workers less productive workers? It depends on the quality of social exchange. Journal of Applied Psychology, 101, 279-291.

McGregor, A., Magee, C.A., Caputi, P., \& Iverson, D. (2016). A job demands-resources approach to presenteeism. Career Development International, 21, 402-418.

Michelson, G., \& Mouly, V.S. (2004). Do loose lips sink ships? The meaning, antecedents and consequences of rumour and gossip in organizations. Corporate Communications, 9, 189201. 
Naseer, S., Raja, U., \& Donia, M.B.L. (2016). Effect of perceived politics and perceived support on bullying and emotional exhaustion: The moderating role of Type A personality. Journal of Psychology, 150, 606-624.

Noon, M., \& Delbridge, R. (1993). News from behind my hand: Gossip in organizations. Organization Studies, 14, 23-36

Oyserman, D. (1993). The lens of personhood: Viewing the self, others, and conflict in a multicultural society. Journal of Personality and Social Psychology, 65, 993-1009.

Oyserman, D., Coon, H.M., \& Kemmelmeier, M. (2002). Rethinking individualism and collectivism: Evaluation of theoretical assumptions and meta-analyses. Psychological Bulletin, 128, 3-72.

Parker, D.F., \& DeCotiis, T.A. (1983). Organizational determinants of job stress. Organizational Behavior and Human Performance, 32, 160-177.

Perko, K., Kinnunen, U., \& Feldt, T. (2017). Long-term profiles of work-related rumination associated with leadership, job demands, and exhaustion: A three-wave study. Work and Stress, 31, 395-420.

Preacher, K.J., \& Hayes, A.F. (2004). SPSS and SAS procedures for estimating indirect effects in simple mediation models. Behavior Research Methods, Instruments, \& Computers, 36, $717-731$.

Preacher, K.J., Rucker, D.D., \& Hayes, A.F. (2007). Assessing moderated mediation hypotheses: Theory, methods, and prescriptions. Multivariate Behavioral Research, 42, 185-227.

Quinn, R.W., Spreitzer, G.M., \& Lam, C.F. (2012). Building a sustainable model of human energy in organizations: Exploring the critical role of resources. Academy of Management Annals, 6, 337-396. 
Robinson, S.L., \& Bennett, R.J. (1995). A typology of deviant behaviors: A multidimensional scaling study. Academy of Management Journal, 38, 555-572.

Russ-Eft, D. (2001). Workload, stress, and human resource development. Human Resource Development Quarterly, 12, 1-3.

Ryan, R.M., \& Deci, E.L. (2000). Self-determination theory and the facilitation of intrinsic motivation, social development, and well-being. American Psychologist, 55, 68-78.

Saks, A., Uggerslev, K.L., \& Fassina, N.E. (2007). Socialization tactics and newcomer adjustment: A meta-analytic review and test of a model. Journal of Vocational Behavior, 70, $413-446$.

Shaukat, R., Yousaf, A., \& Sanders, K. (2017). Examining the linkages between relationship conflict, performance and turnover intentions: Role of job burnout as a mediator. International Journal of Conflict Management, 28, 4-23.

Shrout P.E., \& Bolger, N. (2002) Mediation in experimental and nonexperimental studies: New procedures and recommendations. Psychological Methods 7, 422-455.

Silla, I., \& Gamero, N. (2014). Shared time pressure at work and its health-related outcomes: Job satisfaction as a mediator. European Journal of Work and Organizational Psychology, 23, $405-418$.

Smith, P.B., \& Bond, M. (1993). Social psychology across cultures. Boston: Allyn and Bacon.

So, T.T.C., West, M.A., \& Dawson, J.F. (2011). Team-based working and employee well-being: A cross-cultural comparison of United Kingdom and Hong Kong health services. European Journal of Work and Organizational Psychology, 20, 305-325.

Spector, P.E. (2006). Method variance in organizational research: Truth or urban legend? Organizational Research Methods, 9, 221-232. 
Stiglbauer, B. (2017). Under what conditions does job control moderate the relationship between time pressure and employee well-being? Investigating the role of match and personal control beliefs. Journal of Organizational Behavior, 38, 730-748.

Tang, C. S.-K., Au, W.-T., Schwarzer, R., \& Schmitz, G. (2001). Mental health outcomes of job stress among Chinese teachers: Role of stress resource factors and burnout. Journal of Organizational Behavior, 22, 887-901.

Tangney, J.P., Wagner, P.E., Hill-Barlow, D., Marschall, D.E., \& Gramzow, R. (1996). Relation of shame and guilt to constructive versus destructive responses to anger across the lifespan. Journal of Personality and Social Psychology, 70, 797-809.

Taylor, S.G., \& Kluemper, D.H. (2012). Linking perceptions of role stress and incivility to workplace aggression: The moderating role of personality. Journal of Occupational Health Psychology, 17, 316-329.

Triandis, H.C. (2001). Individualism-collectivism and personality. Journal of Personality, 69, 907-924.

Triandis, H.C., Bontempo, R., Villareal, M., Asai, M., \& Lucca, N. (1988). individualism and collectivism: Cross-cultural perspectives on self-ingroup relationships. Journal of Personality and Social Psychology, 54, 323-338.

Triandis, H.C, \& Gelfand, M.J. (1998). Converging measurement of horizontal and vertical individualism and collectivism. Journal of Personality and Social Psychology, 74, 118-128.

Turnley, W.H., \& Feldman, D.C. (2000). Re-examining the effects of psychological contract violations: Unmet expectations and job dissatisfaction as mediators. Journal of Organizational Behavior, 21, 25-42. 
van Dyne, L., Vandewalle, D., Kostova, T., Latham, M. E., \& Cummings, L. L. (2000).

Collectivism, propensity to trust and self-esteem as predictors of organizational citizenship in a non-work setting. Journal of Organizational Behavior, 21, 3-23.

Wert, S.R., \& Salovey, P. (2004). A social comparison account of gossip. Review of General Psychology, 8, 122-137.

Wicker, E.W., Payne, G.C., \& Morgan, R.D. (1983). Participant descriptions of guilt and shame. Motivation and Emotion, 7, 25-39.

Williams, L.J., \& Anderson, S. E. (1991). Job satisfaction and organizational commitment as predictors of organizational citizenship and in-role behavior. Journal of Management, 17, $601-617$.

Zagenczyk, T.J., Restubog, S.L., Kiewitz, C., Kiazad, K., \& Tang, R.L. (2014). Psychological contracts as a mediator between Machiavellianism and employee citizenship and deviant behaviors. Journal of Management, 40, 1098-1122. 
Figure 1: Conceptual model

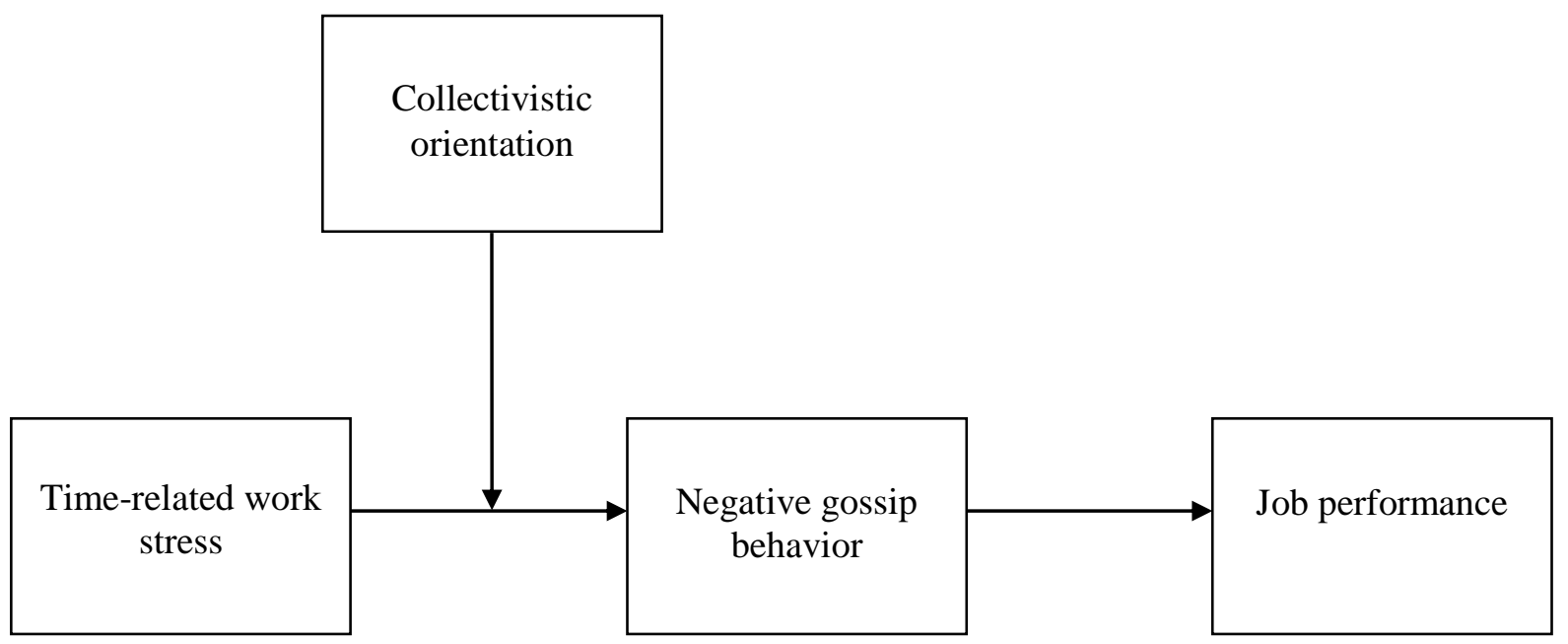


Figure 2: Moderating effect of collectivistic orientation on the relationship between time-related work stress and negative gossip behavior

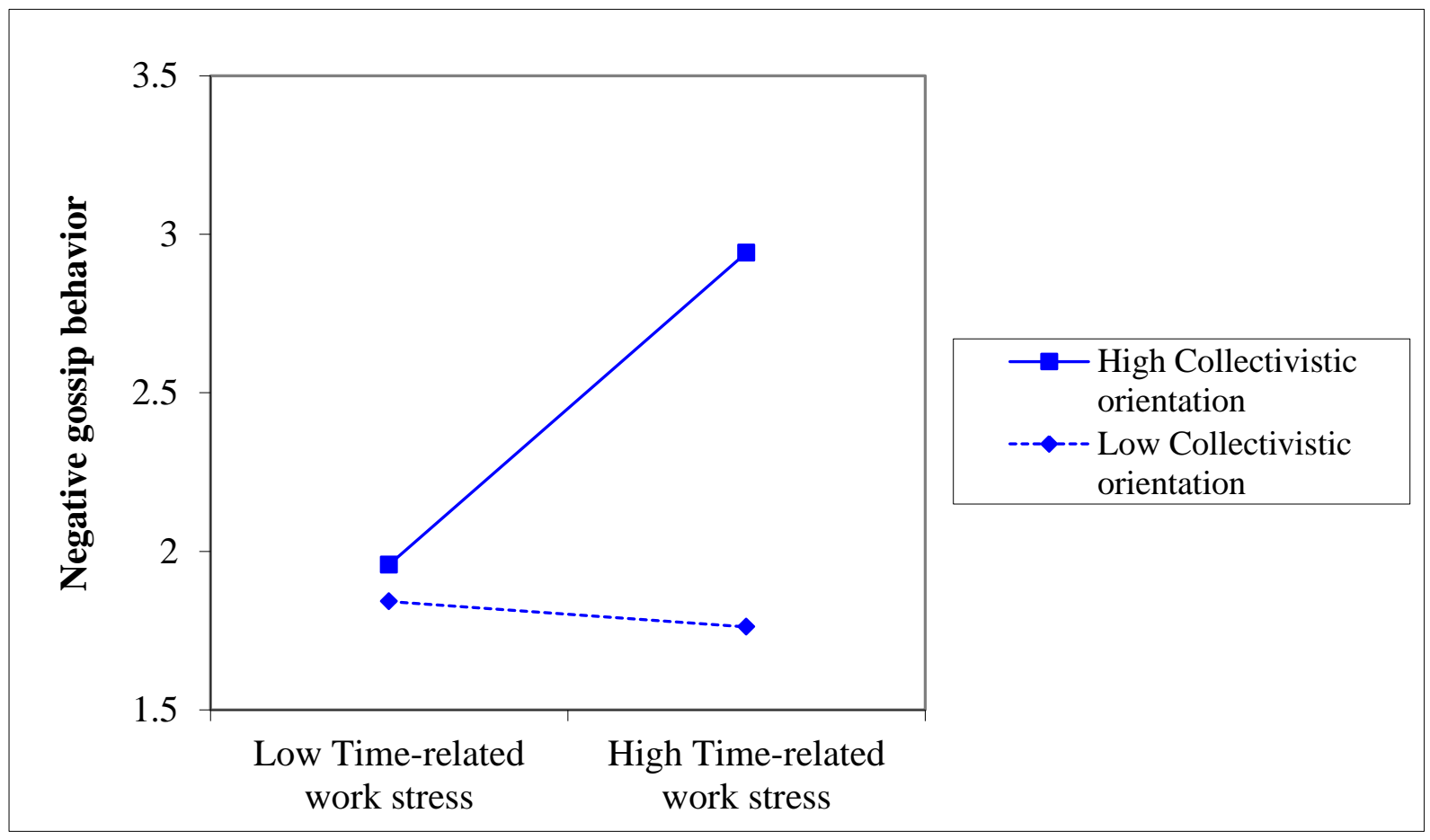


Table 1: Correlation table and descriptive statistics

\begin{tabular}{lccccccc}
\hline & 1 & 2 & 3 & 4 & 5 & 6 & 7 \\
\hline 1. Time-related work stress & & & & & & & \\
2. Collectivistic orientation & $.149^{*}$ & & & & & & \\
3. Negative gossip behavior & $.188^{* *}$ & $.272^{* *}$ & & & & & \\
4. Job performance & -.066 & -.060 & $-.204^{* *}$ & & & & \\
5. Gender & -.105 & -.005 & .056 & $-.146^{*}$ & & & \\
6. Age & $.216^{* *}$ & .039 & .030 & -.122 & $-.268^{* *}$ & & \\
7. Organizational tenure & $.152^{*}$ & -.085 & -.055 & -.066 & $-.256^{* *}$ & $.852^{* *}$ & \\
\hline$\quad$ Mean & 3.585 & 3.866 & 2.765 & 4.058 & .096 & 31.848 & 7.520 \\
\multicolumn{1}{c}{ Standard deviation } & .654 & .695 & .911 & .583 & .295 & 7.448 & 5.492 \\
\hline
\end{tabular}

Notes: $\mathrm{N}=198$.

$* p<.05 ; * * p<.01$. 
Table 2: Regression results

\begin{tabular}{|c|c|c|c|c|c|c|}
\hline & \multicolumn{3}{|c|}{ Negative gossip behavior } & \multicolumn{2}{|c|}{ Job performance } \\
\hline & & Model 1 & Model 2 & Model 3 & Model 4 & Model 5 \\
\hline Gender & & .157 & .112 & .149 & $-.317 *$ & $-.293 *$ \\
\hline Age & & $.038 *$ & .021 & .022 & $-.020 *$ & -.013 \\
\hline Organizational tenure & & $-.045^{*}$ & -.029 & -.029 & .012 & .004 \\
\hline Industry: automobile ${ }^{a}$ & & $-.657 * *$ & $-.649 * *$ & $-.520 *$ & $-.683 * * *$ & $-.806 * * *$ \\
\hline Industry: banking & & -.230 & -.091 & -.080 & $-.198 *$ & $-.234 * *$ \\
\hline Industry: education & & .285 & $.517 *$ & $.555 *$ & $-.274+$ & -.220 \\
\hline Time-related work stress & & & $.306^{* *}$ & $.226^{*}$ & & .024 \\
\hline Collectivistic orientation & & & $.258 * *$ & $.324 * * *$ & & -.033 \\
\hline $\begin{array}{c}\text { Time-related work stress } \times \\
\text { collectivistic orientation }\end{array}$ & & & & $.266^{*}$ & & -.159 \\
\hline Negative gossip behavior & & & & & & $-.293 * * *$ \\
\hline & $\begin{array}{r}\mathrm{R}^{2} \\
\Delta \mathrm{R}^{2}\end{array}$ & .084 & $\begin{array}{c}.170 \\
.086^{* * *}\end{array}$ & $\begin{array}{l}.188 \\
.018^{*}\end{array}$ & .149 & $\begin{array}{l}.208 \\
.059 * *\end{array}$ \\
\hline
\end{tabular}

Notes: $\mathrm{n}=198$ (unstandardized regression coefficients).

${ }^{+} \mathrm{p}<.10 ; * p<.05 ; * * p<.01 ; * * * p<.001$ (two-tailed tests).

${ }^{a}$ The textiles industry is the base category. 